\title{
Utjecaj pH na nastajanje kompleksa L-histidina i bakra
}

\author{
M. Drulak, A. Stanković i M. Medvidović-Kosanović* \\ Sveučilište u Osijeku, Odjel za kemiju, Cara Hadrijana 8A, 31000 Osijek
}

\begin{abstract}
Sažetak
Ispitivan je nastanak kompleksa L-histidina i bakra u omjeru 1:1 u području $\mathrm{pH}$ od $\mathrm{pH}=4$ do $\mathrm{pH}=10$. Istraživanja su provedena u elektrokemijskoj ćeliji, gdje je kao radna elektroda upotrijebljena elektroda od staklastog ugljika, kao referentna $\mathrm{Ag} / \mathrm{AgCl}$ elektroda te kao protuelektroda platinska žica. Utvrđeno je da kompleks bakra i histidina nastaje u području od pH $=6$ do $\mathrm{pH}=10$ te da se oksidacijski potencijal metalnog iona u kompleksu negativira s povećanjem pH. Struja oksidacijskog strujnog vrha raste do $\mathrm{pH}=8$ te nakon toga opada, dok se potencijal oksidacijskog strujnog vrha linearno smanjuje $\mathrm{s}$ povećanjem vrijednosti $\mathrm{pH}$.
\end{abstract}

Ključne riječi

Bakar, ciklička voltametrija, diferencijalna pulsna voltametrija, L-histidin

\section{Uvod}

Bakar je esencijalni element koji u organizam unosimo pomoću hrane kao što su iznutrice, zeleno lisnato povrće, orašasti plodovi i dr. Odrasloj osobi potrebno je oko 1,2 mg bakra dnevno, koji potpomaže prijenos energije u stanice. On se pohranjuje u jetri, mozgu, bubrezima, srcu i poprečno-prugastim mišićima. Neke od uloga bakra su povećanje apsorpcije drugih metala, pomoć u formiranju kolagena, djeluje kao kofaktor za nekoliko enzima i dr. lako je bakar esencijalan element, njegov suvišak je toksičan. ${ }^{1,2}$ Male koncentracije slobodnog bakra imaju sposobnost generiranja slobodnih radikala. Bakar postoji u našem organizmu vezan u metaloproteine ili kao sastav kompleksa molekula male molekularne mase da bi se izbjegla njegova toksičnost. ${ }^{3}$ Jedan od metaloproteina je i kompleks bakra i L-histidina.

L-histidin odnosno 2-amino-3-(4-imidazol) propionska kiselina je aminokiselina koju su, neovisno jedan o drugom, otkrili Hedin i Kossel 1896. godine. Histidin je sastavni dio proteina zajedno s ostalih 19 standardnih aminokiselina. Ta endogeno sintetizirana aminokiselina nalazi se u jetri, mozgu i skeletnim mišićima. ${ }^{4,5}$ Istraživanja su pokazala da je histidin esencijalna aminokiselina za dojenčad i djecu tijekom rasta i razvoja, dok se kod odraslih ljudi dovoljna količina histidina dobiva iz 5-fosfo$\alpha$-D-riboze 1-difosfata. ${ }^{5,6}$ Sadrži tri ionizirajuće skupine: karboksilnu skupinu $\mathrm{s} \quad \mathrm{pK}_{1}=1,82$, amino skupinu $\mathrm{s}$ $\mathrm{pK}_{2}=9,17$ te karakterističnu R-skupinu koju čini imidazolni prsten $\mathrm{s} \mathrm{pK}_{3}=6,00 .^{7}$ Zbog vrijednosti $\mathrm{pK}$ bočnog ogranka, dušik imidazolnog prstena histidina se pri fiziološkim uvjetima pojavljuje u protoniranom i deprotoniranom stanju. Neprotonirana imidazolna skupina je nukleofilna. Bočni ogranak histidina omogućuje mu sudjelovanje u kiselo-baznim katalizama i koordinaciji metalnih iona. ${ }^{5}$ Jedna od značajnijih uloga histidina $u$ našem organizmu je borba protiv oksidativnog stresa, odnosno reaktivnih kisikovih spojeva. ${ }^{8}$ Ta sposobnost histidina pripisuje se njegovom imidazolnom prstenu, koji ima sposobnost hvatanja slobodnih radikala.

Kompleks bakra i L-histidina otkriven je 1966. godine u ljudskoj krvi. Od tada se ispituje uloga histidina u prijenosu bakra u stanice. Istraživanja su pokazala da je kompleks uključen u prijenos bakra do staničnog transportnog sustava.

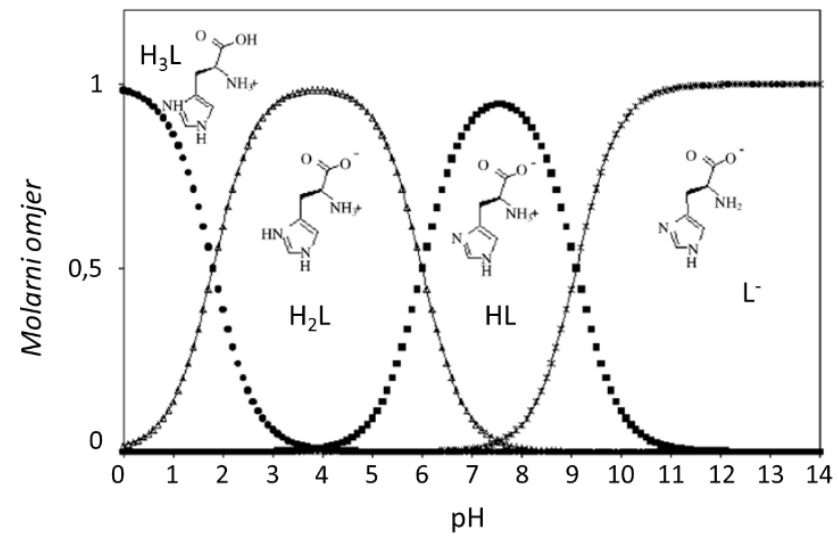

Slika 1 - Dijagram specijacije L-histidina: nedisocirani oblik Lhistidina $\left(\mathrm{H}_{3} \mathrm{~L}\right)$, deprotonirani oblici L-histidina $\left(\mathrm{H}_{2} \mathrm{~L}\right.$, $\left.\mathrm{HL}, \mathrm{L}^{-}\right)^{3}$

Fig. 1 - Speciation diagram of L-histidine: undissociated form of L-histidine, $\left(\mathrm{H}_{3} \mathrm{~L}\right)$, deprotonated forms of L-histidine $\left(\mathrm{H}_{2} \mathrm{~L}, \mathrm{HL}, \mathrm{L}^{-}\right)^{3}$

\footnotetext{
* Autor za dopisivanje: doc. dr.sc. Martina Medvidović-Kosanović e-pošta: mmkosano@kemija.unios.hr
} 
$\mathrm{U}$ rasponu $\mathrm{pH}$ od $\mathrm{pH}=4$ do $\mathrm{pH}=10$ postoje tri oblika histidina: $\mathrm{H}_{2} \mathrm{~L}, \mathrm{HL}$ i $\mathrm{L}^{-}$(slika 1), a u fiziološkoj otopini najučestaliji je HL. Zbog tri potencijalna donorska centra histidin tvori mono i bis metalne komplekse. Uz omjer metala i liganda, veličinu metalnog kationa i pH otopine, na izgled kompleksa utječe i stereokemija kompleksa, jačina veze metal-ligand, energija stabilizacije ligandnog polja i entropija keliranja. Kompleks iona $\mathrm{Cu}^{2+} \mathrm{i}$ histidina stabilniji je u usporedbi s kompleksima s drugim metalnim ionima kao što su $\mathrm{Co}^{2+}, \mathrm{Cd}^{2+}, \mathrm{Zn}^{2+}, \mathrm{Ni}^{2+} \mathrm{i} \mathrm{dr}{ }^{3}$

Neki autori proučavali su komplekse bakra i histidina omjera $1: 1$ i $1: 2$. Kompleksi su kvadratno planarni. U omjeru 1:1 s povećanjem vrijednosti $\mathrm{pH}$ spominju se

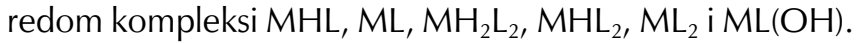
$\mathrm{U}$ omjeru 1:2 pri fiziološkom $\mathrm{pH}$ bakar se veže preko amino i karboksilne skupine jedne molekule histidina te dušika imidazolnog prstena, amino i karboksilne skupine druge molekule histidina. ${ }^{3,9}$

Dosadašnja istraživanja kompleksa bakra s L-histidinom i njegovim dipeptidima uključivala su potenciometriju, UV/VIS, IR i ${ }^{1} \mathrm{H}$ NMR spektroskopiju te kalorimetriju. ${ }^{3,10}$ Cilj ovog istraživanje je doprinijeti boljem razumijevanju nastanka kompleksa L-histidina i bakra u otopini u omjeru $1: 1$, uporabom rijetko primjenjivanih elektrokemijskih metoda (cikličke i diferencijalne pulsne voltametrije). Kompleksi bakra (II) i aminokiselina upotrebljavaju se kao modelni sustavi za ispitivanje farmakološkog utjecaja lijekova te smanjivanje njihove toksičnosti. ${ }^{11}$ Stoga rezultati tog istraživanja mogu naći primjenu u biološkim sustavima.

Tablica 1 - Popis kemikalija, njihovih molekulskih formula i proizvođača, upotrijebljenih u radu

Table 1 - List of chemicals used in this paper, their molecular formulas and manufacturers

\begin{tabular}{|c|c|c|}
\hline $\begin{array}{l}\text { Naziv kemikalije } \\
\text { Name of chemical }\end{array}$ & $\begin{array}{l}\text { Molekulska formula } \\
\text { Molecular formula }\end{array}$ & $\begin{array}{c}\text { Proizvođač } \\
\text { Manufacturer }\end{array}$ \\
\hline $\begin{array}{l}\text { bakrov (II) nitrat trihidrat } \\
\text { copper (II) nitrate trihydrate }\end{array}$ & $\mathrm{Cu}\left(\mathrm{NO}_{3}\right)_{2} \cdot 3 \mathrm{H}_{2} \mathrm{O}$ & $\begin{array}{l}\text { Acros Organics, Thermo Fisher } \\
\text { Scientific, Geel, Belgija } \\
\text { Acros Organics, Thermo Fisher } \\
\text { Scientific, Geel, Belgium }\end{array}$ \\
\hline $\begin{array}{l}\text { (S)-2-amino-3-(4-imidazol)propionska kiselina } \\
\text { (L-histidin) } \\
\text { (S)-2-amino-3-(4-imidazolyl)propionic acid } \\
\text { (L-histidine) }\end{array}$ & $\mathrm{C}_{6} \mathrm{H}_{9} \mathrm{~N}_{3} \mathrm{O}_{2}$ & $\begin{array}{c}\text { Sigma-Aldrich, St. Louis, Missouri, } \\
\text { SAD } \\
\text { Sigma-Aldrich, St. Louis, Missouri, } \\
\text { USA }\end{array}$ \\
\hline $\begin{array}{l}\text { octena kiselina } \\
\text { acetic acid }\end{array}$ & $\mathrm{CH}_{3} \mathrm{COOH}$ & $\begin{array}{c}\text { Kemika, Zagreb, Hrvatska } \\
\text { Kemika, Zagreb, Croatia }\end{array}$ \\
\hline $\begin{array}{l}\text { natrijev acetat } \\
\text { sodium acetate }\end{array}$ & $\mathrm{CH}_{3} \mathrm{COONa}$ & $\begin{array}{l}\text { T.T.T. d. o. o., Sveta Nedjelja, } \\
\text { Hrvatska } \\
\text { T.T.T. d. o. o., Sveta Nedjelja, } \\
\text { Croatia }\end{array}$ \\
\hline $\begin{array}{l}\text { natrijev dihidrogenfosfat } \\
\text { sodium dihydrogen phosphate }\end{array}$ & $\mathrm{NaH}_{2} \mathrm{PO}_{4}$ & $\begin{array}{l}\text { Kemika, Zagreb, Hrvatska } \\
\text { Kemika, Zagreb, Croatia }\end{array}$ \\
\hline $\begin{array}{l}\text { dinatrijev hidrogenfosfat } \\
\text { disodium hydrogen phosphate }\end{array}$ & $\mathrm{Na}_{2} \mathrm{HPO}_{4}$ & $\begin{array}{c}\text { Kemika, Zagreb, Hrvatska } \\
\text { Kemika, Zagreb, Croatia }\end{array}$ \\
\hline $\begin{array}{l}\text { natrijev tetraborat dekahidrat } \\
\text { sodium tetraborate decahydrate }\end{array}$ & $\mathrm{Na}_{2} \mathrm{~B}_{4} \mathrm{O}_{7} \cdot 10 \mathrm{H}_{2} \mathrm{O}$ & $\begin{array}{c}\text { Sigma-Aldrich, St. Louis, Missouri, } \\
\text { SAD } \\
\text { Sigma-Aldrich, St. Louis, Missouri, } \\
\text { USA }\end{array}$ \\
\hline $\begin{array}{l}\text { klorovodična kiselina } \\
\text { hydrochloric acid }\end{array}$ & $\mathrm{HCl}$ & $\begin{array}{c}\text { Kemika, Zagreb, Hrvatska } \\
\text { Kemika, Zagreb, Croatia }\end{array}$ \\
\hline $\begin{array}{l}\text { natrijev hidroksid } \\
\text { sodium hydroxide }\end{array}$ & $\mathrm{NaOH}$ & $\begin{array}{l}\text { T.T.T. d. o. o., Sveta Nedjelja, } \\
\text { Hrvatska } \\
\text { T.T.T. d. o. o., Sveta Nedjelja, } \\
\text { Croatia }\end{array}$ \\
\hline $\begin{array}{l}\text { natrijev hidrogenkarbonat } \\
\text { sodium hydrogen carbonate }\end{array}$ & $\mathrm{NaHCO}_{3}$ & $\begin{array}{l}\text { T.T.T. d. o. o., Sveta Nedjelja, } \\
\text { Hrvatska } \\
\text { T.T.T. d. o. o., Sveta Nedjelja, } \\
\text { Croatia }\end{array}$ \\
\hline
\end{tabular}


Tablica 2 - Priprema uzoraka otopina L-histidina $\left(c=1 \cdot 10^{-4} \mathrm{~mol} \mathrm{dm}^{-3}\right)$ i bakrova nitrata $\left(c=1 \cdot 10^{-4} \mathrm{~mol} \mathrm{dm}^{-3}\right)$ te kompleksa L-histidina i bakrova nitrata omjera $1: 1 \mathrm{u}$ puferima od $\mathrm{pH}=4$ do $\mathrm{pH}=10$

Table 2 - Samples preparation of L-histidine $\left(c=1 \cdot 10^{-4} \mathrm{~mol} \mathrm{dm}{ }^{-3}\right)$, copper nitrate $\left(c=1 \cdot 10^{-4} \mathrm{~mol} \mathrm{dm}^{-3}\right)$, and L-histidine and copper complex in $1: 1$ ratio in a buffers from $\mathrm{pH}=4$ to $\mathrm{pH}=10$

\begin{tabular}{|c|c|c|c|}
\hline $\begin{array}{l}\text { Uzorak } \\
\text { Sample }\end{array}$ & $\begin{array}{l}V(\text { pufer }) / \mathrm{cm}^{3} \\
V(\text { buffer }) / \mathrm{cm}^{3}\end{array}$ & $\begin{array}{c}V\left(0,01 \mathrm{~mol} \mathrm{dm}^{-3} \text { L-histidin }\right) / \mathrm{cm}^{3} \\
V\left(0.01 \mathrm{~mol} \mathrm{dm}^{-3} \text { L-histidine }\right) / \mathrm{cm}^{3}\end{array}$ & $\begin{array}{l}V\left(0,01 \mathrm{~mol} \mathrm{dm}^{-3} \mathrm{Cu}\left(\mathrm{NO}_{3}\right)\right) / \mathrm{cm}^{3} \\
V\left(0.01 \mathrm{~mol} \mathrm{dm}^{-3} \mathrm{Cu}\left(\mathrm{NO}_{3}\right)\right) / \mathrm{cm}^{3}\end{array}$ \\
\hline $\begin{array}{l}\text { pufer }(\mathrm{pH}=4-10) \\
\text { buffer }(\mathrm{pH}=4-10)\end{array}$ & 15,00 & / & / \\
\hline $\begin{array}{l}\text { otopina L-histidine } \\
\text { solution of L-histidine }\end{array}$ & 14,85 & 0,15 & I \\
\hline $\begin{array}{l}\text { otopina bakrova nitrata } \\
\text { solution of copper nitrate }\end{array}$ & 14,85 & I & 0,15 \\
\hline $\begin{array}{l}\text { otopina L-histidina i bakrova } \\
\text { nitrata } 1: 1 \\
\text { solution of L-histidine and } \\
\text { copper nitrate } 1: 1\end{array}$ & 14,70 & 0,15 & 0,15 \\
\hline
\end{tabular}

\section{Eksperimentalni dio}

\subsection{Kemikalije i priprava uzoraka}

Kemikalije upotrijebljene za izradu ovog istraživanja navedene su u tablici 1. Otopine su priređene u vodi Milli$\mathrm{Q}\left(\kappa \leq 5,6 \cdot 10^{-8} \mathrm{~S} \mathrm{~cm}^{-1}\right)$. Početne koncentracije otopina L-histidina i bakrova nitrata iz kojih su se priređivali uzorci iznosile su $1 \cdot 10^{-2} \mathrm{~mol} \mathrm{dm}^{-3}$. Puferi vrijednosti $\mathrm{pH}=4,5$ i 6 priređeni su iz octene kiseline i natrijeva acetata, $\mathrm{pH}=7$ i 8 iz natrijeva dihidrogenfosfata i dinatrijeva hidrogenfosfata, $\mathrm{pH}=9$ iz natrijeva tetraborata dekahidrata i klorovodične kiseline, a $\mathrm{pH}=10$ iz natrijeva hidrogenkarbonata i natrijeva hidroksida. Priređeni puferi upotrijebili su se za pripravu uzoraka za mjerenje. U tablici 2 navedena je priprava uzoraka L-histidina i bakrova nitrata koncentracije $c=1 \cdot 10^{-4} \mathrm{~mol} \mathrm{dm}^{-3}$ te kompleksa L-histidina i bakrova nitrata omjera $1: 1$ u puferima $\mathrm{pH}=4-10$. Ukupan volumen ispitivanog uzorka iznosio je $15 \mathrm{~cm}^{3}$. Čiste otopine pufera rabile su se za slijepu probu. Uzorak L-histidina, odnosno bakrova nitrata $\left(c=1 \cdot 10^{-4} \mathrm{~mol} \mathrm{dm}^{-3}\right.$ ) priređen je dodavanjem $0,15 \mathrm{~cm}^{3}$ L-histidina, odnosno bakrova nitrata u $14,85 \mathrm{~cm}^{3}$ pufera. Kompleks L-histidina i bakrova nitrata omjera $1: 1$ pripravljen je dodavanjem $0,15 \mathrm{~cm}^{3}$ otopine L-histidina $\mathrm{i}$ $0,15 \mathrm{~cm}^{3}$ otopine bakrova nitrata u $14,70 \mathrm{~cm}^{3}$ pufera.

\subsection{Aparatura i uvjeti mjerenja}

Mjerenja su izvedena pomoću potenciostata/galvanostata PalmSens (PalmSens BV, Utrecht, Nizozemska) pri sobnoj temperaturi $\left(\theta=25 \pm 1{ }^{\circ} \mathrm{C}\right)$ u Faradayevu kavezu, a za akviziciju i obradu podataka primijenjen je softver PSTrace 4.4. Troelektrodni sustav sastojao se od radne elektrode od staklastog ugljika površine $0,018 \mathrm{~cm}^{2}$ (ALS Co., Japan), referentne $\mathrm{Ag} / \mathrm{AgCl}$ elektrode s $3 \mathrm{~mol} \mathrm{dm}^{-3} \mathrm{NaCl}$ kao unutarnjim elektrolitom (ALS Co., Japan) i protuelektrode platinske žice (ALS Co., Japan). Prije svakog mjerenja uzorak je propuhivan argonom $\operatorname{Ar} 5$ ( $\left.\phi_{\mathrm{Ar}}=99,999 \%\right)$ 4- 5 min. Radna elektroda se čistila elektrokemijski u $1 \mathrm{~mol} \mathrm{dm}^{-3} \mathrm{H}_{2} \mathrm{SO}_{4}$, gdje je raspon potencijala iznosio od $-1,0 \vee$ do $1,0 \mathrm{~V}$, brzina promjene potencijala $50 \mathrm{mV} \mathrm{s}^{-1}$, a ukupan broj ciklizacija iznosio je $10(n=10)$. Brzina promjene potencijala kod cikličke voltametrije iznosila je $100 \mathrm{mVs}^{-1}$ i rađene su 3 ciklizacije $(n=3)$. Uvjeti diferencijalne pulsne voltametrije bili su: "scan increment" $5 \mathrm{mV}$, visina pulsa $25 \mathrm{mV}$, širina pulsa $70 \mathrm{~ms}$ te brzina promjene potencijala $5 \mathrm{mV} \mathrm{s}^{-1}$.

\section{Rezultati i rasprava \\ 3.1. Ciklička voltametrija}

Elektrokemijska svojstva L-histidina ispitivana su u puferima od $\mathrm{pH}=4$ do $\mathrm{pH}=10$. Cikličkom volta-metrijom utvrđeno je da aminokiselina L-histidin nije elektroaktivna (nisu se pojavili anodni, odnosno katodni strujni vrhovi). Ciklički voltamogram otopine bakrova nitrata pokazuje anodne $\mathrm{i}$ katodne strujne vrhove $\mathrm{u}$ ispitivanim puferima. $\mathrm{Na}$ slici 2 prikazan je ciklički voltamogram otopine L-histidina $\left(c=1 \cdot 10^{-4} \mathrm{~mol} \mathrm{dm}^{-3}\right)$, otopine bakrova nitrata $\left(c=1 \cdot 10^{-4} \mathrm{~mol} \mathrm{dm}^{-3}\right)$ i L-histidina $\mathrm{i}$ bakrova nitrata $\mathrm{u}$ omjeru $1: 1 \mathrm{u}$ puferu $\mathrm{pH}=4$. Ciklički voltamogram L-histidina $\mathrm{u}$ puferu $\mathrm{pH}=4$ pokazuje da L-histidin nije elektroaktivan. Ciklički voltamogram bakrova nitrata pokazuje anodne (A1) i katodne (C1) strujne vrhove koji su posljedica oksidacije, odnosno redukcije slobodnog bakra. Ciklički voltamogram L-histidina i bakrovog nitrata u omjeru $1: 1$ u puferu $\mathrm{pH}=4$ pokazuje mali pomak vrha oksidacijskog strujnog vala (A1) prema negativnim vrijednostima potencijala te povećanje oksidacijske struje, u odnosu na otopinu bakrova nitrata, što pokazuje da pri $\mathrm{pH}=4$ nastaje određena količina $[\mathrm{Cu}(\mathrm{HisH})]^{2+}$ kompleksa, L-histidina i $\mathrm{Cu}^{2+}$ iona. ${ }^{3}$ 


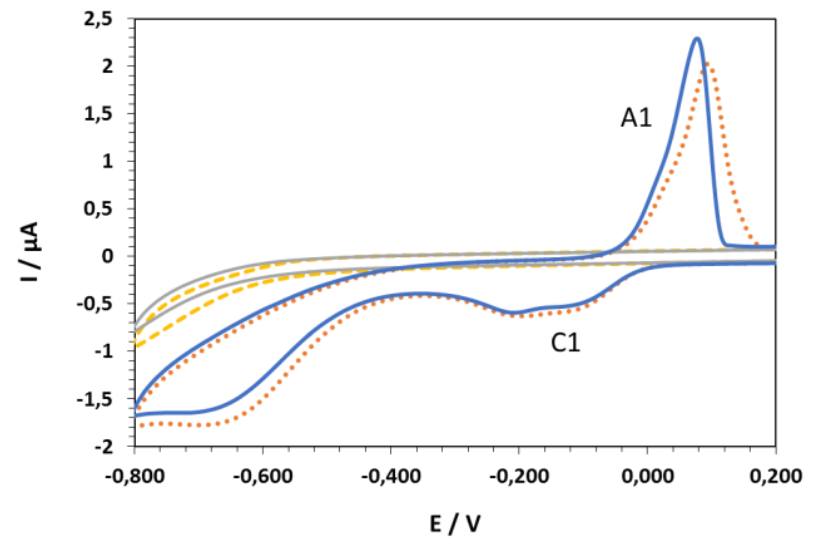

Slika 2 - Ciklički voltamogrami otopine pufera $\mathrm{pH}=4(\square)$, otopine L-histidina $\left(c=1 \cdot 10^{-4} \mathrm{~mol} \mathrm{dm}^{-3}\right) \quad(-)$, otopine bakrova nitrata $\left(c=1 \cdot 10^{-4} \mathrm{~mol} \mathrm{dm}^{-3}\right)(\bullet \bullet \bullet)$ i L-histidina i bakrova nitrata $\mathrm{u}$ omjeru $1: 1(\square)$ snimljeni na elektrodi od staklastog ugljika u puferu $\mathrm{pH}=4$ pri brzini polarizacije elektrode $100 \mathrm{mV} \mathrm{s}^{-1}$

Fig. 2 - Cyclic voltammograms of buffer solution $\mathrm{pH}=4(\square)$, L-histidine $\left(c=1 \cdot 10^{-4} \mathrm{~mol} \mathrm{dm}^{-3}\right)(-)$, copper nitrate $\left(c=1 \cdot 10^{-4} \mathrm{~mol} \mathrm{dm}^{-3}\right)(\bullet \bullet \bullet)$, and L-histidine and copper nitrate in $1: 1$ ratio $(-)$, obtained on the glassy carbon electrode in buffer $\mathrm{pH}=4$ at scan rate $100 \mathrm{mV} \mathrm{s}^{-1}$

Na slici 3 prikazani su ciklički voltamogrami L-histidina i bakrova nitrata $\left(c=1 \cdot 10^{-4} \mathrm{~mol} \mathrm{dm}^{-3}\right)$ u omjeru $1: 1$. Pri $\mathrm{pH}=4$ javlja se oksidacijski strujni vrh koji je posljedica nastanka određene količine $[\mathrm{Cu}(\mathrm{HisH})]^{2+}$ kompleksa Lhistidina i bakra. $\mathrm{Na} \mathrm{pH}=6$ dolazi do stvaranja kompleksa $[\mathrm{Cu}(\mathrm{His})]^{+}$između L-histidina i iona bakra. ${ }^{3}$ Pri toj $\mathrm{pH}$ vrijednosti dva deprotonirana oblika histidina, $\mathrm{H}_{2} \mathrm{~L}$ i HL, u jednakim su molarnim omjerima. Na slici je vidljivo da povećanjem vrijednosti $\mathrm{pH}(\mathrm{pH} \geq 6)$ dolazi do smanjenja anodnog strujnog vrha bakra kao posljedica vezanja iona bakra za ligand $\mathrm{i}$ javlja se novi strujni vrh koji je posljedica oksidacije metalnog centra $[\mathrm{Cu}(\mathrm{His})(\mathrm{OH})]$ kompleksa. ${ }^{3}$ Navedeni strujni vrh se pojavljuje pri potencijalu od $-0,1 \mathrm{~V}$.

\subsection{Diferencijalna pulsna voltametrija}

Diferencijalnom pulsnom voltamametrijom utvrđena je elektroaktivnost L-histidina samo pri $\mathrm{pH}=10$ kada je L-histidin potpuno deprotoniran. Oksidacijski strujni vrh (A3) pojavio se na potencijalu $0,8 \mathrm{~V}$, što odgovara oksidaciji imidazolnog prstena (slika 4). ${ }^{12,13}$ Vidljiva su i dva anodna strujna vrha bakrova nitrata pri potencijalima $E=0,025 \mathrm{~V}$ (A1) i $E=0,075 \mathrm{~V}$ (A2) koji odgovaraju oksidaciji $\mathrm{Cu}^{0} \mathrm{u} \mathrm{Cu}^{+}$te $\mathrm{Cu}^{+}$u $\mathrm{Cu}^{2+}$.

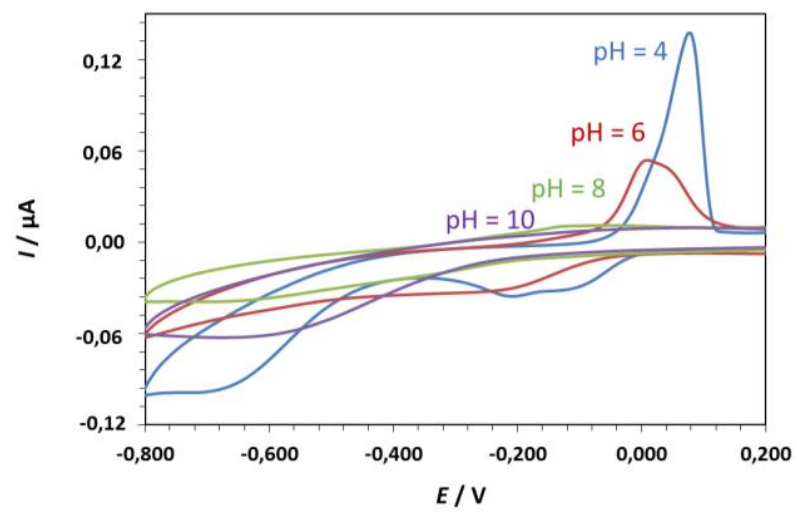

Slika3 - Ciklički voltamogrami L-histidina i bakrova nitrata $\left(c=1 \cdot 10^{-4} \mathrm{~mol} \mathrm{dm}^{-3}\right) \quad u$ omjeru $1: 1$ snimljeni na elektrodi od staklastog ugljika pri brzini polarizacije elektrode $100 \mathrm{mV} \mathrm{s}^{-1}$ pri različitim vrijednostima $\mathrm{pH}$ : $\mathrm{pH}=4(\square), \mathrm{pH}=6(\square), \mathrm{pH}=8(\square) \mathrm{i} \mathrm{pH}=10(\square)$

Fig. 3 - Cyclic voltammograms of L-histidine and copper nitrate ( $c=1 \cdot 10^{-4} \mathrm{~mol} \mathrm{dm}^{-3}$ ) in $1: 1$ ratio, obtained on the glassy carbon electrode at scan rate $100 \mathrm{mVs}^{-1}$ at different $\mathrm{pH}$ values: $\mathrm{pH}=4(\square), \mathrm{pH}=6(\square), \mathrm{pH}=8$ $(\square)$ and $\mathrm{pH}=10(\square)$

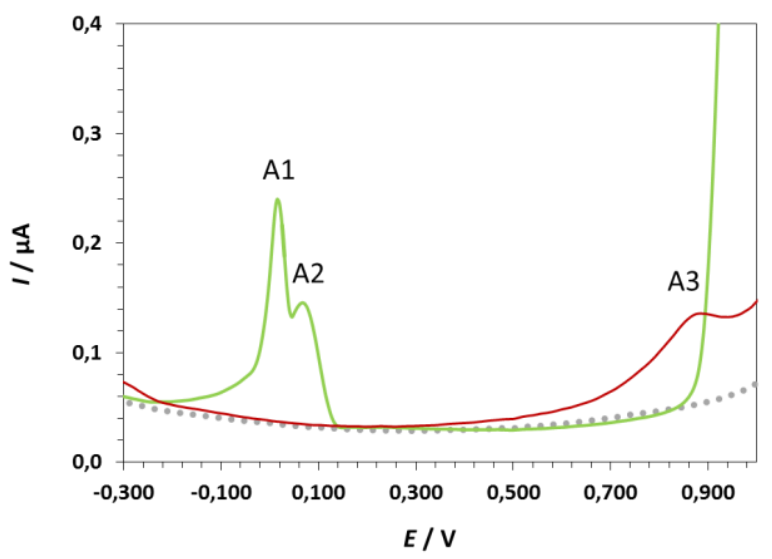

Slika 4 - Diferencijalni pulsni voltamogrami otopine pufera $\mathrm{pH}=10(\bullet \bullet)$, bakrova nitrata $\left(c=1 \cdot 10^{-4} \mathrm{~mol} \mathrm{dm}^{-3}\right)$ $(-)$ i L-histidina $\left(c=1 \cdot 10^{-4} \mathrm{~mol} \mathrm{dm}^{-3}\right)(\square)$ snimljeni na elektrodi od staklastog ugljika u puferu $\mathrm{pH}=10$. Brzina polarizacije elektrode, $5 \mathrm{mV} \mathrm{s}^{-1}$.

Fig. 4 - Differential pulse voltammograms of blank solution $(\bullet \bullet \bullet)$, copper nitrate $\left(c=1 \cdot 10^{-4} \mathrm{~mol} \mathrm{dm}^{-3}\right)(\Longrightarrow)$ and L-histidine $\left(c=1 \cdot 10^{-4} \mathrm{~mol} \mathrm{dm}^{-3}\right)(-)$, obtained on the glassy carbon electrode in a buffer $\mathrm{pH}=10$. Scan rate, $5 \mathrm{mV} \mathrm{s}^{-1}$.

Na slici 5 prikazani su diferencijalni pulsni voltamogrami L-histidina $\left(c=1 \cdot 10^{-4} \mathrm{~mol} \mathrm{dm}^{-3}\right) \quad \mathrm{i}$ bakrova nitrata ( $c=1 \cdot 10^{-4} \mathrm{~mol} \mathrm{dm}^{-3}$ ) u omjeru $1: 1$. Na slici je vidljivo da se povećanjem vrijednosti $\mathrm{pH}$ oksidacijski strujni vrh (A2) smanjuje, dok se oba strujna vrha (A1 i A2) negativiraju s povećanjem vrijednosti $\mathrm{pH}$. 


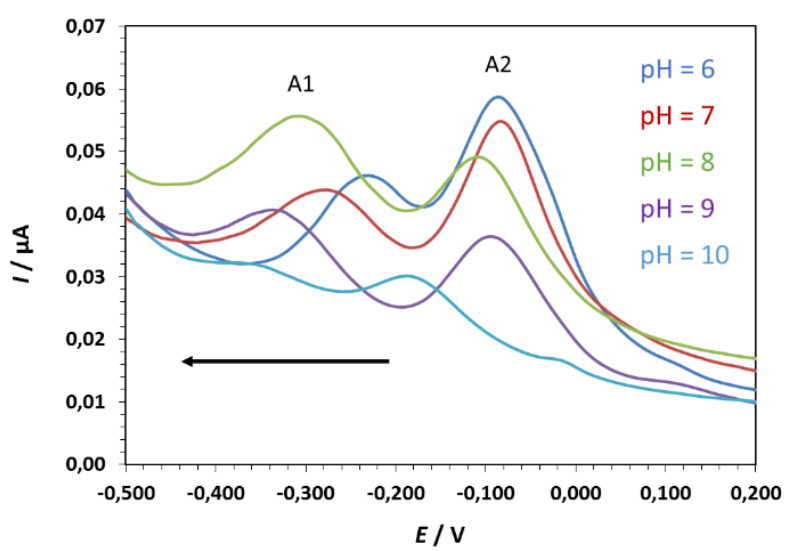

Slika 5 - Diferencijalno pulsni voltamogrami kompleksa L-histidina i $\mathrm{Cu}^{2+}$ iona $\left(\mathrm{c}=1 \cdot 10^{-4} \mathrm{~mol} \mathrm{dm}^{-3}\right)$ u omjeru $1: 1$ snimljeni na elektrodi od staklastog ugljika pri brzini polarizacije elektrode $5 \mathrm{mV} \mathrm{s}^{-1}$ pri različitim vrijednostima $\mathrm{pH}$ : $\mathrm{pH}=6(\square), \mathrm{pH}=7(\square), \mathrm{pH}=8$ $(\square), \mathrm{pH}=9(\square)$ i $\mathrm{pH}=10(\square)$

Fig. 5 - Differential pulse voltammograms of L-histidine and $\mathrm{Cu}^{2+}$ ion $\left(c=1 \cdot 10^{-4} \mathrm{~mol} \mathrm{dm}^{-3}\right)$ complex in $1: 1$ ratio obtained on the glassy carbon electrode at scan rate $5 \mathrm{mV} \mathrm{s}^{-1}$ at different $\mathrm{pH}$ values: $\mathrm{pH}=6(\square), \mathrm{pH}=7$ $(\square), \mathrm{pH}=8(\square), \mathrm{pH}=9(\square) \mathrm{i} \mathrm{pH}=10(\square)$

Tablica 3 prikazuje vrijednosti struje anodnog strujnog vrha, $I_{\mathrm{p}}$ i potencijala anodnog strujnog vrha, $E_{\mathrm{p}}$ za strujni vrh kompleksa L-histidina i bakra (A1), pri vrijednostima $\mathrm{pH}$ od $\mathrm{pH}=6$ do $\mathrm{pH}=10$, uzete sa slike 5. Podatci navedeni u tablici 3 prikazani su na slici 6 . Na slici $6 \mathrm{~A}$ vidljivo je da struja anodnog strujnog vrha metalnog centra kompleksa raste do $\mathrm{pH}=8 \mathrm{i}$ nakon toga opada. Slika 6B prikazuje ovisnosti potencijala anodnog strujnog vrha, $E_{\mathrm{p}} \mathrm{O}$ vrijednosti $\mathrm{pH}$ otopine kompleksa bakra i L-histidina omjera $1: 1$. Potencijal oksidacijskog strujnog vrha linearno se smanjuje s povećanjem vrijednosti $\mathrm{pH}$, što upućuje na oksidacijski mehanizam koji uključuje izmjenu jednakog broja protona i elektrona.

Tablica 3 - Prikaz struje anodnog strujnog vrha, $I_{p}$ i potencijala anodnog strujnog vrha, $E_{\mathrm{p}}$ kompleksa L-histidina $\mathrm{i}$ $\mathrm{Cu}^{2+}$ iona $\left(\mathrm{c}=1 \cdot 10^{-4} \mathrm{~mol} \mathrm{dm}^{-3}\right)$ omjera $1: 1$ pri različitim vrijednostima $\mathrm{pH}$

Table 3 - Anodic peak current, $I_{\mathrm{p}}$ and anodic peak potential, $E_{\mathrm{p}}$ values of L-histidine, and $\mathrm{Cu}^{2+}$ ion ( $c=1 \cdot 10^{-4} \mathrm{~mol} \mathrm{dm}^{-3}$ ) complex in $1: 1$ ratio at different $\mathrm{pH}$ values

\begin{tabular}{l|c|c}
\hline $\mathrm{pH}$ & $10^{2} \cdot I_{\mathrm{p}}(\mathrm{A} 1) / \mu \mathrm{A}$ & $E_{\mathrm{p}} / \mathrm{mV}$ \\
\hline 6 & 4,606 & $-0,2352$ \\
7 & 4,372 & $-0,2789$ \\
8 & 5,560 & $-0,3089$ \\
9 & 4,070 & $-0,3352$ \\
10 & 3,205 & $-0,3629$ \\
\hline
\end{tabular}

\section{Zaključak}

L-histidin je aminokiselina od velike važnosti u ljudskom organizmu. Jedna od njegovih glavnih uloga je keliranje metalnih kationa. $U$ ovom je radu ispitano nastajanje kompleksa L-histidina i bakra u području $\mathrm{pH}$ od $\mathrm{pH}=4$ do $\mathrm{pH}=10$ cikličkom i diferencijalnom pulsnom voltametrijom. Rezultati su pokazali da u ispitivanom području $\mathrm{pH}$ nastaju kompleksi L-histidina i $\mathrm{Cu}^{2+}$ iona. Struja oksidacijskog strujnog vrha kompleksa L-histidina i bakra raste do $\mathrm{pH}=8$, a nakon toga opada. Potencijal oksidacijskog strujnog vrha linearno se smanjuje s povećanjem vrijednosti $\mathrm{pH}$ ispitivanih otopina, što upućuje na oksidacijski mehanizam koji uključuje izmjenu jednakog broja elektrona i protona.
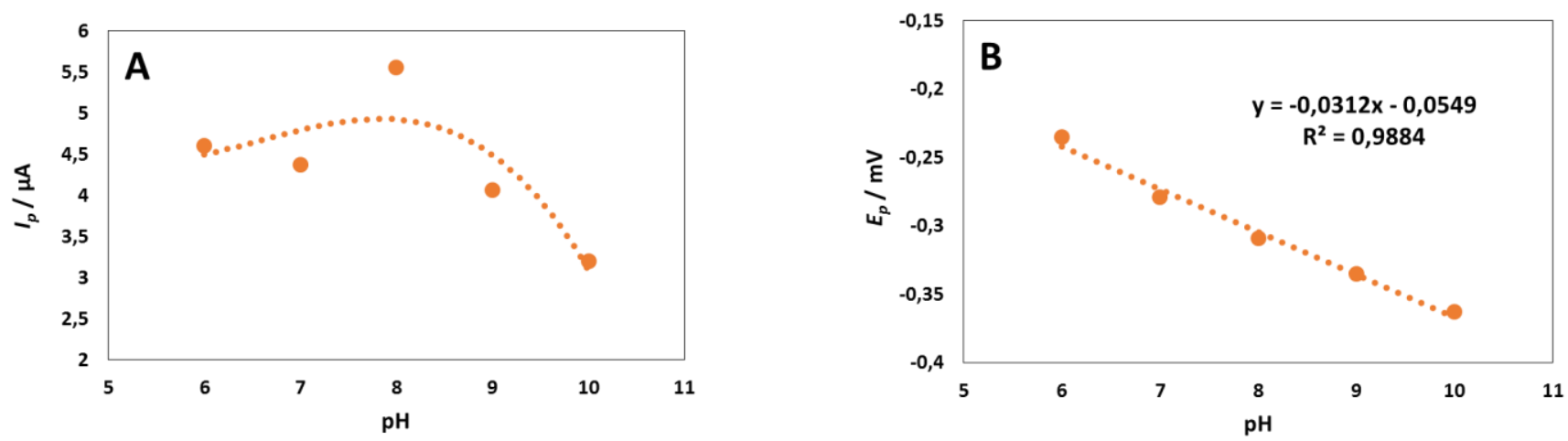

Slika 6 - Prikaz ovisnosti struje anodnog strujnog vrha, $I_{\mathrm{p}}(6 \mathrm{~A})$ i ovisnosti potencijala anodnog strujnog vrha, $E_{\mathrm{p}}(6 \mathrm{~B})$ o vrijednosti pH otopine kompleksa L-histidina i $\mathrm{Cu}^{2+}$ iona $\left(c=1 \cdot 10^{-4} \mathrm{~mol} \mathrm{dm}^{-3}\right)$ u omjeru $1: 1$

Fig. 6 - Anodic peak current, $I_{\mathrm{p}}(6 \mathrm{~A})$ and anodic peak potential, $E_{\mathrm{p}}(6 \mathrm{~B})$ dependence on $\mathrm{pH}$ value of L-histidine and $\mathrm{Cu}^{2+}$ ion (c $\left.=1 \cdot 10^{-4} \mathrm{~mol} \mathrm{dm}^{-3}\right)$ complex solution in $1: 1$ ratio 


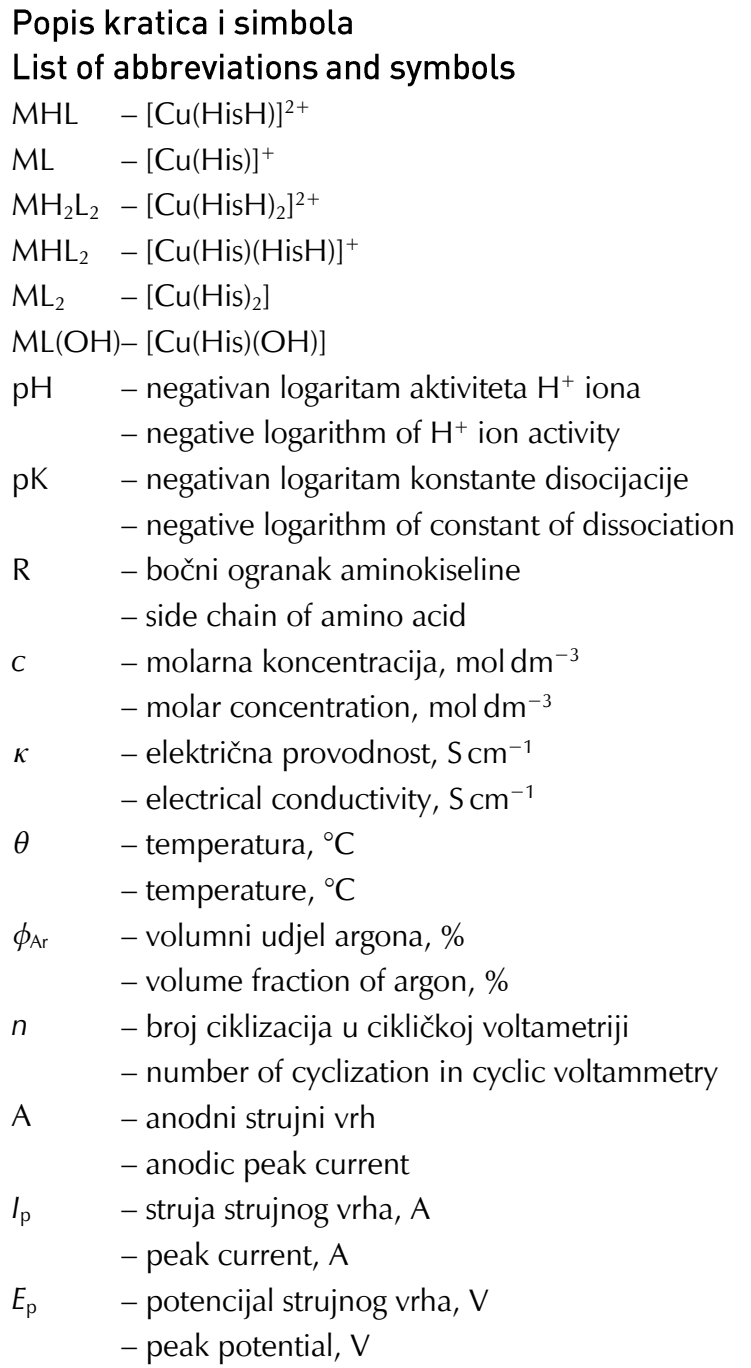

\section{Literatura}

\section{References}

1. URL: http://www.rsc.org/periodic-table/element/29/copper (15.3.2018.)

2. D. Ghosh, P. S. Singha, S. B. Firdaus, P. Parida, D. Ghosh, Biometals in health and disease: A review, World Res. J. Pharmaceut. Res. 5 (2016) 390-399.
3. P. Deschamps, P. P. Kulkarni, M. Gautam-Basak, B. Sarkar, The saga of copper(II)-L-histidine, Coord. Chem. Rev. 249 (2005) 895-909, doi: https://doi.org/ 10.1016/ j.ccr.2004.09.013.

4. A. Abbaspour, M. A. Kamyabi, Characterization and determination of stability constants of copper(II)-I-histidine complexation system by using multivariate curve resolution method of visible spectra and two hard modeling methods in aqueous solutions, Anal. Chim. Acta 512 (2004) 257-269, doi: https://doi.org/10.1016/j.aca.2004. 02.056.

5. R. A. Ingle, Histidine Biosynthesis, The Arabidopsis Book 9 (2011) e0141, doi: https://doi.org/10.1199/tab.0141.

6. URL: https://biocyc.org/META/new-image?object=HISTSYNPWY (16. 3. 2018.).

7. URL: http://oregonstate.edu/instruct/bb350/ahernmaterials/ a03/03p35.jpg (16. 3. 2018.).

8. J. Bai, Nannan-Yu, H. Mu, L. Dong, X, Zhang, Histidine protects human lens epithelial cells against $\mathrm{H}_{2} \mathrm{O}_{2}$-induced oxidative stress injury through the NF-к B pathway, J. Cell. Biochem. 119 (2018) 1637-1645, doi: https://doi.org/10.1002/jcb.26323.

9. L. Gala, M. Lawson, K. Jomova, L. Zelenicky, A. Congradyova, M. Mazur, M. Valko, EPR Spectroscopy of a Clinically Active (1:2) Copper(II)-Histidine Complex Used in the Treatment of Menkes Disease: A Fourier Transform Analysis of a Fluid CWEPR Spectrum, Molecules 19 (2014) 980-991, doi: https://doi.org/10.3390/molecules 19010980.

10. I. Sovago, E. Farkas, A. Gergely, Studies on Transition-metalPeptide Complexes. Part 7. Copper(i1) Complexes of Dipeptides containing L-Histidine, J. Chem. Soc. Dalton Trans. $381 \quad$ (1982) 2159-2163, doi: https://doi.org/10.1039/DT9820002159.

11. A. El-Said, A. S. A. Zidan, M. S. El-Meligy, A. A. Aly, O. F. Mohammed, Coordination Properties of Some Mixed Amino Acid Metal Complexes, Synth. React. Inorg, Met-Org Chem. 31 (4) (2001) 633-648, doi: https://doi.org/10.1081/SIM100104792.

12. L.-C. Chen, C.-C. Chang, H.-C. Chang, Electrochemical oxidation of histidine at an anodic oxidized boron-doped diamond electrode in neutral solution, Electrochim. Acta 53 (2008) 2883-2889, doi: https://doi.org/10.1016/j.electacta.2007.10.071.

13. M. Medvidović-Kosanović, A. Stanković, M. Drulak, M. SakBosnar, Potentiometric, electrochemical and UV/VIS investigation of a copper (II) complex with $\beta$-alanyl-Lhistidine, Int. J. Electrochem. Sci. 13 (2018) 5323-5332, doi: https://doi.org/10.20964 /2018.06.52. 


\section{SUMMARY}

\section{Influence of $\mathrm{pH}$ on Formation of L-histidine and Copper Complex}

Mateja Drulak, Anamarija Stanković, and Martina Medvidović-Kosanović*

Formation of L-histidine and copper complex in $1: 1$ ratio in the $\mathrm{pH}$ range from $\mathrm{pH}=4$ to $\mathrm{pH}=10$ was studied. Experiments were conducted in an electrochemical cell with a working glassy carbon electrode, reference $\mathrm{Ag} / \mathrm{AgCl}$ electrode and a platinum wire counter electrode. The results have shown that copper and histidine complex is formed in the range from $\mathrm{pH}=6$ to $\mathrm{pH}=10$ and that the oxidation potential of metal ion in the complex became more negative with the increase in $\mathrm{pH}$. Oxidation peak current increased until $\mathrm{pH}=8$, and thereafter decreased, while oxidation peak potential linearly decreased with increase in $\mathrm{pH}$ value.

\section{Keywords}

Copper, cyclic voltammetry, differential pulse voltammetry, L-histidine 
